\title{
Collaborative, Risk-Informed, Triple Bottom Line, Multi-Criteria Decision Analysis Planning Framework for Integrated Urban Water Management
}

\author{
Jeanne Cole ${ }^{1, *}$, Sybil Sharvelle ${ }^{1}$, Neil Grigg ${ }^{1}$, Gary Pivo ${ }^{2}$ and Jon Haukaas ${ }^{3}$ \\ 1 Civil \& Environmental Engineering Department, Colorado State University, Fort Collins, CO 80523, USA; \\ sybil.sharvelle@colostate.edu (S.S.); Neil.Grigg@colostate.edu (N.G.) \\ 2 College of Architecture, Planning \& Landscape Architecture, University of Arizona, Tucson, AZ 85719, USA; \\ gpivo@email.arizona.edu \\ 3 Water Engineering \& Field Services, City of Fort Collins, CO 80521, USA; JHAUKAAS@msn.com \\ * Correspondence: cole.jeanne@gmail.com; Tel.: +44-794-960-2196
}

Received: 24 October 2018; Accepted: 21 November 2018; Published: 24 November 2018

check for updates

\begin{abstract}
The historical division of water management into different sectors, with financially and technologically driven decision processes, makes taking a more holistic approach to finding sustainable solutions for urban water management difficult. Here, a planning framework for Integrated Urban Water Management (IUWM) that evolved during a two-year study evaluating alternative strategies for dual water supply within a local government context is described. The planning framework was developed to overcome the obstacles that surfaced over the course of the study. It provides a structured approach to strategic decision making that integrates triple bottom line (TBL), multi-criteria decision analysis (MCDA), uncertainty and sensitivity analyses, and participatory decision making into an exploration of water supply alternatives. TBL assured stakeholders that the decisions considered the financial, social, and environmental performance. MCDA provided visibility into the benefits and trade-offs of the alternatives by providing a quantitative method for comparing alternatives that incorporates incommensurate performance indicators and priorities of multiple stakeholders. Uncertainty and sensitivity analyses addressed concerns regarding decision risk and improved transparency into inputs driving uncertainty in the analysis. Finally, a flexible participatory process helped to circumvent socio-institutional barriers by adapting the methodology and increasing cooperation among stakeholders and multidisciplinary experts. The resulting collaborative, risk-informed, TBL-MCDA (CRTM) planning framework helps to refine the feasible set of alternatives by providing more transparency into the drivers, technologies, and stakeholders influencing the decision. The planning framework increased the number of participants that were involved in the study, increased interaction between participants, changed the structure of the decision problem, increased the number of performance indicators considered, and improved stakeholder cooperation in the decision process.
\end{abstract}

Keywords: integrated urban water management; multi-criteria decision analysis; planning framework

\section{Introduction}

Urban water management is a critical component of urban livability providing sanitation, safe drinking water, urban drainage and protection from flooding, nutrients and water for agriculture, aesthetics and recreation, and protection of the environment and water sources [1]. Water system maintenance is challenged by difficulties in financing the replacement of aging water infrastructure, climate change, changing populations, urban consolidation, environmental degradation, and public 
understanding of the value of water systems and services [2-4]. To respond, managers need a new approach that includes integrated urban water systems and distributed systems strategies; considers financial, social, and environmental costs and benefits; and, employs an adaptive, participatory approach to decision making [5-7]. Conventional water management approaches may no longer be suitable to meet future challenges. Marlow et al. [2] shows how the 'option space', a sub-set of feasible alternatives, is influenced by actors (participants that are involved in the water infrastructure decision process), technology (solutions available and the confidence in performance), and drivers (goals, constraints, and other factors) in integrated urban water management (IUWM) decision making. A planning framework for urban water infrastructure decision making is needed that allows for inclusion of integrated and distributed urban water strategies in the option space, considers all the costs and benefits, and takes a more agile and inclusive approach to decision making.

The last century's financially-driven, technocratic water management methods resulted in the separation of technological solutions into different water sectors, isolating them from their social and environmental contexts and from broader urban planning [8]. The unintended consequences of these methods include inefficient use of water, poor nutrient control, wasted energy, and insufficient institutional capacity to adapt to the complexity of social-ecological systems with new technological solutions $[2,9,10]$.

Integrated urban water management (IUWM) offers an adaptive and iterative process to overcome these limitations, and align urban development and basin management, by engaging local communities in solving problems through the efficient integration of water sources, water use sectors, and water services at different scales [8]. Like similar frameworks, including sustainable urban water management, total water management, and One Water, IUWM attempts to [2,8,11,12]:

- balance economic development, social equity, and environmental sustainability;

- $\quad$ support a flexible, transdisciplinary approach involving multiple stakeholders and public engagement;

- cultivate a holistic view that recognizes relationships among the water, land use, real estate, and energy sectors;

- create a more natural water cycle that addresses urban water way disconnections;

- increase flexibility and resiliency of urban water systems;

- enhance water security through local source diversification with non-traditional water sources;

- implement a fit-for-purpose approach that matches water quality with the intended use;

- promote water recycling and energy and nutrient recovery; and,

- use water and energy resources efficiently.

Despite discussion of IUWM approaches in the literature [2,5,13], few successful implementations have been reported. Key obstacles include lock-in effects from legacy systems, a risk-averse culture with little tolerance for uncertainty, increased complexity, biases toward technocratic solutions, financially driven decisions, decreasing government budgets, vertical and horizontal institutional fragmentation, and a lack of collaborative governance and community participation $[2,5,9,13]$. More guidance is needed for water managers in how to overcome obstacles to IUWM when defining the option space. Marlow et al. [2] identified two feedback loops, a hard loop that is focused on asset management metrics and soft loop driven by stakeholder perceptions of responsibilities, values, risk tolerance, and willingness to pay, driving investment decisions. The soft loop is likely responsible for the low level of adoption of alternative strategies [2] and highlights the need for methodologies to improve stakeholder visibility into all of the costs and benefits of competing strategies. This soft feedback loop concept that was introduced by Marlow et al. [2] is used throughout this paper.

Researchers have offered several conceptual frameworks to address obstacles to IUWM. The American Water Works Association (AWWA), United States Environmental Protection Agency (USEPA), and American Society of Civil Engineers (ASCE) promote triple bottom line (TBL) analysis for water infrastructure decision making to encourage more sustainable practices [14-16]. TBL structures the decision problem into economic, social, and environmental dimensions and it maintains separate 
bottom lines to include all costs and benefits [17]. Several studies have used MCDA, which provides a computational method for analyzing a set of decision alternatives (discrete decision space) over incommensurable criteria with different weights of importance [18], in water resources management decision problems [19-24]. Hyde et al. [25] and Scholten et al. [26] applied uncertainty analysis to address decision risk due to future uncertainty in a water resource development problem and a water supply infrastructure problem. Scholten et al. [26] and Karaca et al. [23] address uncertainty with MCDA and alternative future scenarios. Other authors have applied social learning frameworks to address socio-institutional barriers to IUWM $[10,27,28]$. The planning framework that is presented here provides a structured approach to high-level strategic decision making through the integration of triple bottom line (TBL), multi-criteria decision analysis (MCDA), uncertainty and sensitivity analyses, and participatory decision making.

This paper discusses how several of the previously referenced obstacles were encountered during a two-year study in Fort Collins, Colorado, which explored alternative strategies for dual water supply within a local government context. The large number of study participants from diverse city departments made a collaborative and flexible approach essential. The initial decision methodology was adapted to address the obstacles and participants' needs encountered during the study. A Collaborative, Risk-informed, TBL-MCDA (CRTM) planning framework for IUWM evolved through the integration of various strategies suggested in the literature for overcoming obstacles to water resources and environmental decision making. The CRTM framework addresses the challenges of organizational fragmentation and bias toward technocratic solutions with a flexible transdisciplinary process involving multidisciplinary experts and stakeholders. It uses a hybrid TBL-MCDA approach to decision making that seeks to fully consider and provide transparency into the financial, social, and environmental benefits and trade-offs of the alternatives considered. Finally, it uses uncertainty and global sensitivity analyses to address decision risk and problem complexity by evaluating the reliability of the results under uncertainty and improving transparency into the inputs driving uncertainty in the results.

This paper focuses on the approach that is taken in the study, the evolution of the framework, and the impacts it had on the study. It is organized into four main sections. Section 2 introduces the case study where the proposed framework was applied. It describes the original approach proposed for the study and the methodological changes needed for project success that led to the evolution of the proposed framework. Section 3 explains the methodology used in the CRTM planning framework. Section 4 shows how the CRTM framework impacted the approach taken in the case study. Finally, Section 5 discusses how the framework addresses barriers to IUWM identified in the literature and the broader applications of the framework. Technical details and results for the dual water systems study can be found in Cole et al. [29]. Although the CRTM framework was only applied to a local case study, it has the potential to be applicable to other public infrastructure decisions involving complex systems with multiple stakeholders.

\section{Study to Assess Alternatives for Dual Water Supply}

The City of Fort Collins is committed to sustainability in their approach to planning for the future, which involves a dynamic process that includes systems thinking, continuous improvement, and TBL analysis [30]. Water managers at the utility saw the replacement of their aging water supply distribution system as an opportunity to improve the water supply infrastructure to better meet the city's future water needs and sustainability goals. These goals included improving drinking water quality, promoting more efficient use of water and energy resources, enhancing the city's water corridors, improving community livability, and facilitating sustainable regional benefits $[29,30]$. The Water Engineering and Field Services Operations Manager discussed ideas for separate water supply via dual distribution systems with Colorado State University (CSU) faculty, which led to a two-year study where Fort Collins Utilities commissioned CSU to explore the topic further [29]. The study evaluated four alternatives for the dual supply of raw and treated water, in addition 
to maintaining the existing conventional system. The first three alternatives used the existing distribution system to supply raw water for irrigation and fire supply, but they considered varying scales of decentralized water treatment and new potable distribution (centralized water treatment and dual distribution, neighborhood scale water treatment and neighborhood dual distribution, and point-of-entry water treatment with single distribution of raw water). The fourth alternative utilized the existing network of irrigation ditches throughout the city to supply raw water for seasonal irrigation (separated irrigation systems).

The study participants were comprised of four main groups, the project team, internal and external experts, and the stakeholder group. The initial interdisciplinary project team was comprised of managers from three departments within the utility (water engineering \& field services, water treatment, and water resources) and researchers from the Civil \& Environmental Engineering Department at CSU. Internal experts were experts outside the initial project team from a different city or CSU departments. External experts were the other experts consulted who did not work for the city or the university. The stakeholder group included the project team and representatives from multiple city departments comprising the Nature in the City Group (NICG). The stakeholder group did not include the public, but the NICG had direct engagement with residents, community and business partners, the Mayor, and City council members through participation in a project that focuses on improving the community's access to nature. The NICG focuses on how to enhance the city's natural areas to support more diverse social and ecological opportunities [31].

Although the city is committed to collaborative governance and sustainability in future planning, there is no standard method for incorporating systems thinking, TBL analysis, and continuous improvement in a collaborative decision process. Like other cities, departments are organized by technical specialty and they tend to work independent of one another. This posed a methodological problem for the project team. How could it foster collaboration among departments needed for systems thinking and continuous improvement and conduct a quantitative, reproducible triple bottom line analysis of the alternatives?

\subsection{Original Methodology}

The original methodology proposed for the study incorporated TBL and MCDA in the analysis, but took a linear, technocratic approach that was driven by the project team, with limited opportunity for stakeholder participation (Figure 1). The project team was responsible for identifying alternatives and structuring the problem; expert consultation was intended to guide alternative designs; and, stakeholder input was limited to weighting the criteria used in the decision analysis.

The City of Fort Collins uses TBL for future planning and decision making to ensure a comprehensive consideration of all the benefits and trade-offs that are associated with a project from an economic, human, and environmental perspective [30]. Evaluating alternative urban water strategies through TBL is not new. Chen and Wang [32] conducted a TBL cost-benefit analysis by monetizing social and environmental benefits, and Kang and Lansey [33] and Liner and deMonsabert [34] applied optimization methods to multi-objective water supply problems to demonstrate the tradeoffs between TBL objectives. Karaca et al. [23] conducted a qualitative TBL analysis of water and energy infrastructure using MCDA and scenario planning. These studies provide insight into criteria and methodologies that can aid decision makers by improving transparency into the benefits and tradeoffs between economic, social, and environmental objectives. However, they do not address the inclusion of competing stakeholder priorities in the decision-making process.

Hajkowicz and Collins [20] suggest using MCDA in water resources decision problems to provide transparency and accountability in the decision process; include and facilitate conflict resolution among multiple stakeholders; provide a logical and robust framework for decision making; and, allow for the inclusion of important non-financial factors (e.g., water quality, greenhouse gas emissions, improvements to urban natural areas, affordability) in the decision-making process. Using MCDA in 
this way provides a structured methodology for exploring the option space and narrows the field of feasible alternatives.

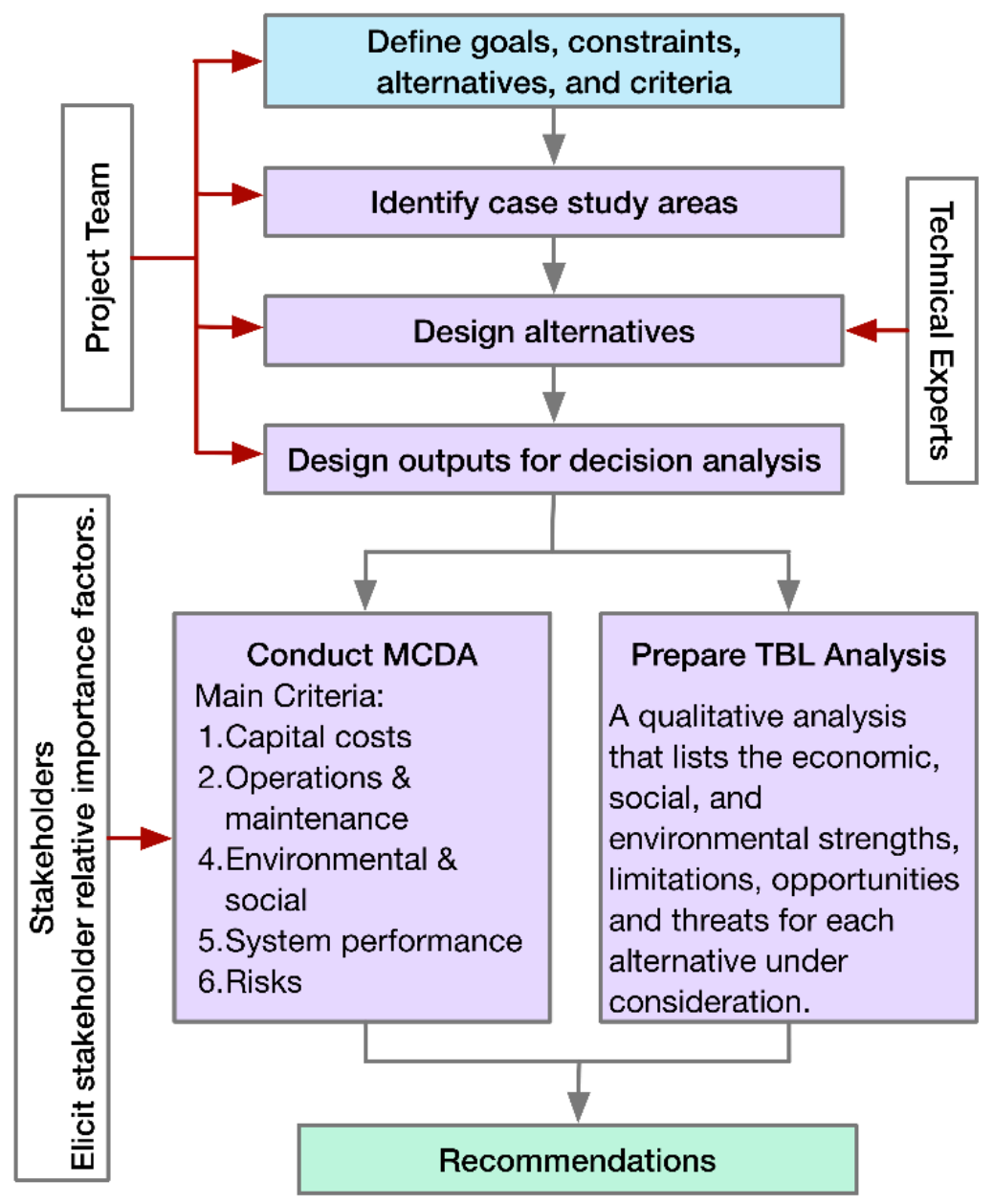

Figure 1. Original approach.

The original methodology proposed using MCDA to evaluate the alternatives' performance on the criteria that were identified by the project team with the results being aggregated to provide a single bottom line (Figure 1). Independent of the MCDA, the city's existing TBL tool, based off the City of Olympia and Evergreen State Sustainability Action Map [35,36], would be used to complete a TBL analysis for each alternative (Figure 1). The city's TBL tool listed an alternative's strengths, limitations, and opportunities from an economic, social, and environmental perspective, but did not provide a quantitative method for computing the bottom lines. The MCDA results and TBL lists would have been used to make recommendations for future strategies.

\subsection{Stakeholder and Project Team Identified Needs for Project Success}

The decisions that were made in the study could have affected several other departments within the utility, the city, and the broader region, making collaboration essential to the study's success. Collaboration was pursued through a transparent, cooperative, and adaptive process that was focused on improving participant knowledge, understanding the problem from multiple perspectives, and remaining open to stakeholder feedback to ensure alignment with city goals and community priorities. Engaging in this process surfaced several additional needs for project success. 


\subsubsection{Need for More Inclusive Participation}

Due to the exploratory nature of the study, consultation with utility experts led to the identification of other experts to consult, ideas for other alternatives to consider, and a larger perspective of the problem. The original approach (Figure 1) needed to be more agile to accommodate a continuously evolving problem structure as a larger, more diverse group of experts were consulted.

The first stakeholder meeting with the NICG sought to explain and validate the project, methods, alternatives, evaluation criteria, and elicit stakeholder preferences. The project team arrived with a set of highly technical criteria that also included a small number of social and environmental criteria. The original criteria were grouped under five main criteria: capital costs, operations and maintenance, social and environmental, system performance, and risks (Figure 1). However, during and after the first stakeholder workshop, it was clear that stakeholders wanted more meaningful participation. They felt that the original criteria did not adequately address ecological and social concerns. They identified several missing criteria and felt their involvement in defining the criteria used to evaluate the option space was important to ensure a comprehensive analysis of the alternatives.

The initial technocratic approach did not fully consider the soft feedback loop and the need to integrate a wide variety of stakeholder values, interests, and priorities in the identification and analysis of alternative strategies. It assumed that the non-technical stakeholders (NICG) would be satisfied with a level of participation typical to other MCDA studies where they rate the relative importance of the performance metrics defined by experts. The result was that stakeholders did not feel empowered in the decision process and they were unwilling to participate further if changes were not made.

\subsubsection{Comprehensive TBL Approach}

The NICG also believed that the decision methodology deviated too far from the TBL approach that city staff had become accustomed to using. They were unclear about how the proposed decision analysis methods would interface with TBL in the final decision. Their other concern was that since social and environmental performance indicators were all included under one of the five main criteria (Figure 1), financial, social, and environmental performance did not have equal standing in the decision analysis. This reflects the non-compensability issue that was brought up in the literature in the 'strong' versus 'weak' sustainability debate where there is disagreement on whether human-made capital assets can substitute natural capital assets as long as the aggregated income does not decrease over time (weak sustainability) [37]. Strong sustainability advocates argue these are not interchangeable, as social and economic systems depend on natural capital. Therefore, natural capital must be protected to ensure the success of future generations [37].

\subsubsection{Uncertainty and Decision Risk}

Enabling a larger group of experts and stakeholders from different backgrounds to define the problem structure increased the complexity of the decision problem. How would decision risk from uncertainty in the applied MCDA methodology, stakeholder preferences, and inputs used to assess alternative performance be dealt with in the decision analysis? How could the project team identify key inputs driving uncertainty in alternative performance and simplify the decision model for future analysis? Finally, how should major future changes that could alter the structure of the decision problem be addressed?

\section{CRTM Planning Framework}

The unanticipated stakeholder and project team concerns and reluctance of stakeholders to participate further without changes led the project team to re-evaluate the methodology. Several modifications were made to address concerns and regain stakeholder commitment to the study. The CRTM planning framework (Figure 2) evolved from the needs that were identified for project success. The new framework addressed the methodological concerns by integrating the three pillars of 
sustainability into the decision model with a new hybrid TBL-MCDA approach, decreased decision risk with the inclusion of uncertainty and sensitivity analyses and scenario planning, and included a more flexible participatory approach throughout the decision process. The hybrid TBL-MCDA provided structure for complex IUWM decision problems by ensuring that the financial, social, and environmental bottom lines have equal representation in the final decision. Inclusion of uncertainty and sensitivity analysis provided insight into performance under future uncertainty and transparency into the model inputs driving the decision process. Scenario planning would enable the evaluation of extreme future scenarios that cannot be addressed with uncertainty analysis. Finally, including the NICG, multidisciplinary experts, and managers throughout the process enabled a holistic transdisciplinary approach to urban water management decision-making, fostered better alignment with city goals, and identified conflicts and opportunities for collaboration with other city departments.

\subsection{Hybrid TBL-MCDA Approach}

In a study evaluating sustainability in asset management in the Australian water sector, water professionals agreed that water authorities needed to embed sustainability into decision tools and move away from thinking of sustainability as a 'bolt-on issue' to be successful [38]. The NICG in the dual water supply study expressed the same sentiment. The original approach, like other studies that applied MCDA to evaluate water management alternatives, used a combination of financial, social, and environmental criteria to calculate one aggregate score rather than a score in each bottom line $[39,40]$. However, in Fort Collins, the visibility of alternatives' performance on each bottom line was important to stakeholders. The CRTM framework took a new hybrid TBL-MCDA approach (Figure 3), which integrated TBL into the MCDA and maintained separation between financial, social, and environmental performance. The main criteria were evaluated through each TBL lens to ensure the comprehensive consideration of the impacts and ensured the three dimensions of sustainability had equal representation in the decision process.

The criteria used in the MCDAs were developed by defining the main criteria for the evaluation of the alternatives, then evaluating the main criteria from each dimension of sustainability to define the performance indicators that were used to measure the performance of the alternatives on each bottom line (details can be found in Cole et al. [29]). The new criteria and performance indicators were defined by the project team based on the original criteria and feedback from the NICG. Then, stakeholder preferences on the relative importance of the main criteria for each bottom line were elicited while using a direct rating method [41]. This ensured each bottom line had equal standing in the final decision and allowed stakeholders to decide how important each criterion was to financial, social, and environmental performance. Outputs were developed to enable participants to readily assess the performance from each TBL lens for each alternative based on average scores using stakeholder preferences in each TBL category (Figure 4; refer to [29] for study methodology and results).

\subsection{Addressing Decision Risk}

Decision risk concerns included increasing complexity due to a larger, more diverse group of participants defining the problem structure, the MCDA technique selected, uncertainty regarding model inputs, and uncertainty in assumptions that were made about the future when defining the problem. The project team also wanted to improve transparency in the decision process by identifying key inputs driving uncertainty in the decision analysis results. 


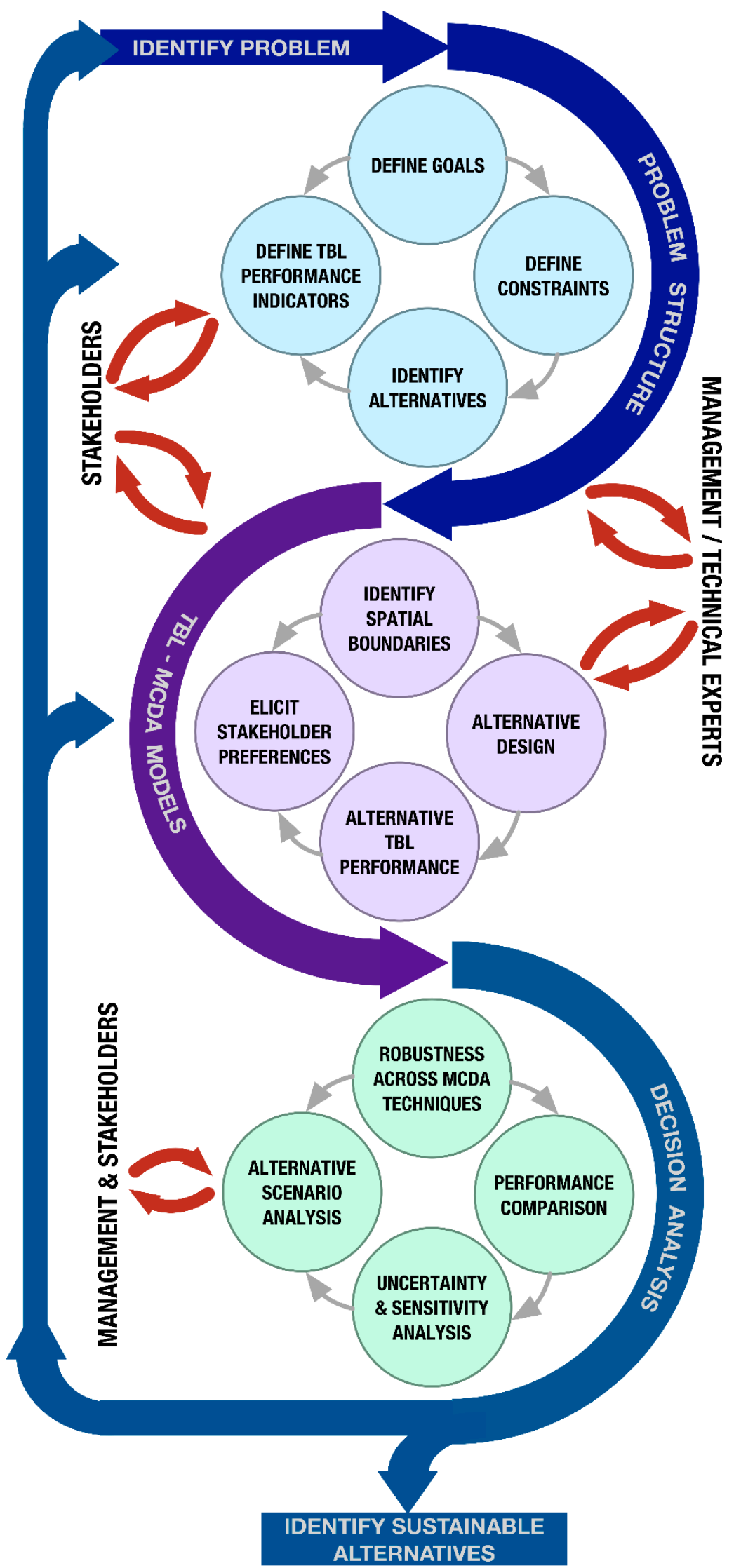

Figure 2. Collaborative, Risk-informed, Triple bottom line-Multi-criteria decision analysis (CRTM) planning framework. 


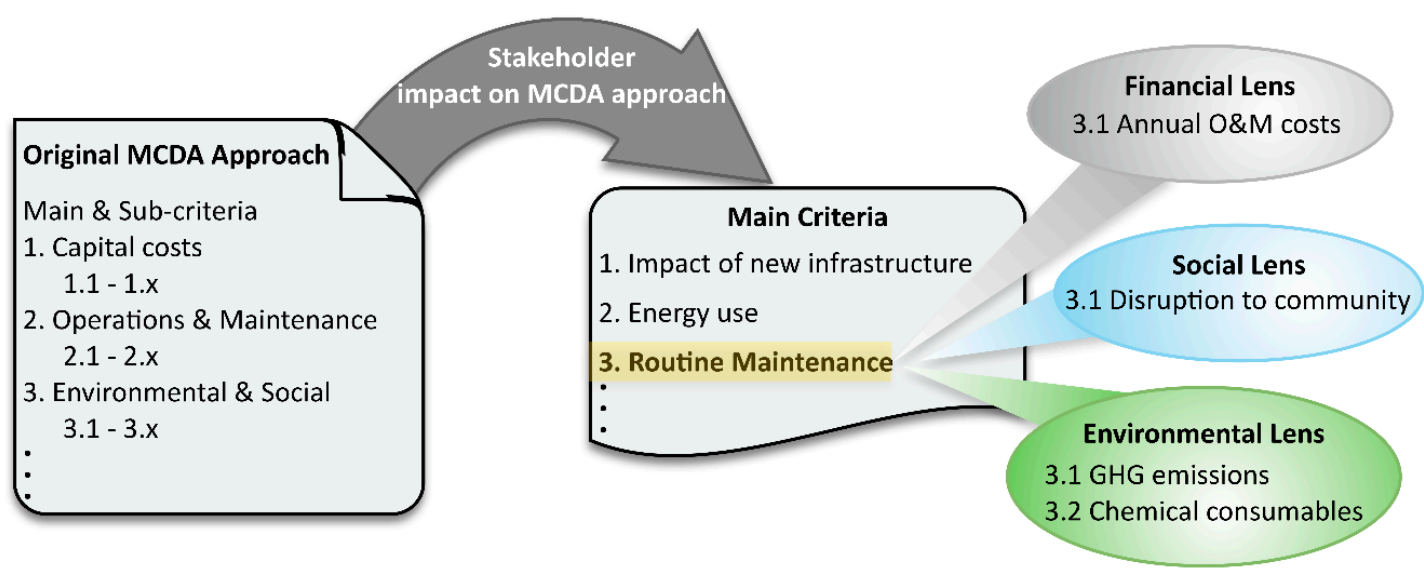

Figure 3. Hybrid multi-criteria decision analysis-triple bottom line (MCDA-TBL) Approach.

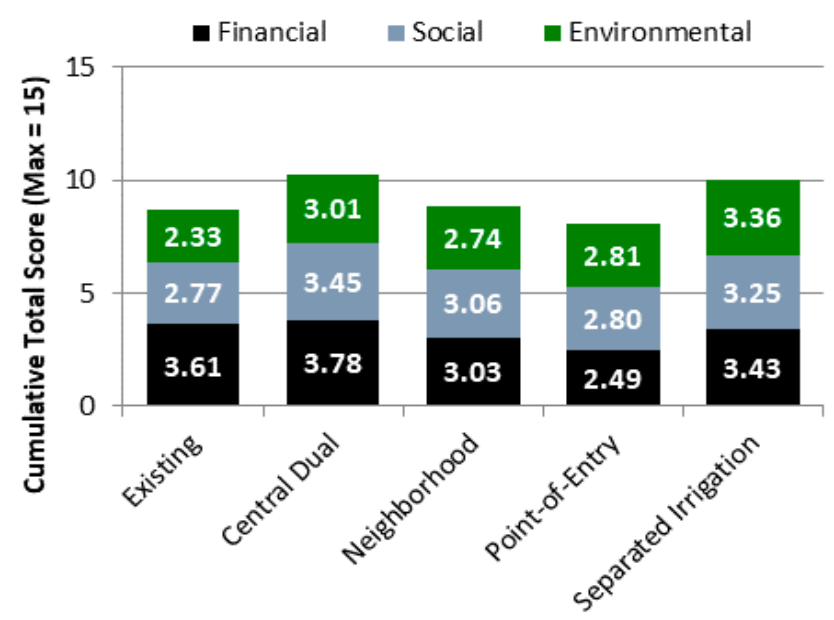

Figure 4. TBL-MCDA average stakeholder results for sample neighborhood 1 (Best score for each bottom line $=5 \&$ Best cumulative score $=15)($ Reproduced with permission from [42]).

\subsubsection{Robustness across MCDA Methods}

The most commonly used MCDA methods in water resources planning and management decision problems are compromise programming, analytical hierarchy process, the preference ranking organization method for enrichment evaluation (PROMETHEE) and elimination and choice expressing reality (ELECTRE) outranking methods, and the weighted sum method (WSM) [20,41,43]. Recent water resources and environmental studies compared the results of several MCDA techniques on the same problem and found that, regardless of the technique applied, the alternative rankings only vary slightly and there is rarely a change in the top ranked alternative [21,43,44]. However, Hajkowicz and Higgins [44] found a slightly larger risk of change in alternative ranking with analyses that include a mix of quantitative and qualitative criteria. Stakeholder involvement in defining the criteria that were used in this study increased the number of criteria in the decision analysis, as well as the number of qualitative criteria. Therefore, there was a need to confirm the decision results while using more than one MCDA technique.

Analytical hierarchy process and outranking methods are better suited for a mix of qualitative and quantitative data, but they are more complex and less transparent to stakeholders [41,45]. Howard [46], Janssen [22], and Zanakis et al. [47] all found methods that are easy for stakeholders to understand, such as the weighted sum method, facilitate user acceptance and buy-in in the decision-making process. Belton and Stewart [45] recommend using a simpler method with stakeholders to avoid stakeholder confusion, and doing a comparison analysis using other techniques later in the analysis stage for a comparison of the results. As a result, the WSM was used initially and then compared to an analysis using an outranking method (PROMETHEE II) to confirm the decision results [29]. 
Other criticisms of MCDA include poor problem structuring that omits important criteria or alternatives, valuation and scaling effects from reducing multi-dimensional problems to a single dimension for aggregation, difficulty in accounting for uncertainties in model inputs, and failure to account for extreme future scenarios in the analysis [41,48]. Integrating a participatory approach throughout the decision process helped to reduce omission risk. Using multiple MCDA techniques helped address uncertainty due to the valuation and scaling techniques applied in the weighted sum MCDA technique. The remaining issues were addressed later with the integration of uncertainty and sensitivity analyses and scenario planning into the framework.

\subsubsection{Uncertainty and Sensitivity Analyses}

Services from water infrastructure may be relied upon for 100 years or more. Therefore, decisions about planning and management of urban water supply infrastructure are made under deep uncertainty [49]. Public sector decisions are conducted under a high degree of public scrutiny, and uncertainty must be acknowledged, rigorously quantified, and considered in any decision process. Uncertainty and sensitivity analyses can decrease decision risk and improve transparency into the key inputs driving the decisions. Therefore, these approaches are essential for robust decision making and the evaluation of alternatives under future uncertainty [50]. Uncertainty and sensitivity analyses improve decision analysis by examining the reliability of the MCDA results given uncertainty in criteria weights and performance indicator input factors, identifying key inputs driving uncertainty in the decision model results and identifying options for model simplification $[25,26,51]$.

Most MCDA sensitivity analyses in the water resources planning and management field use one-at-a-time or local sensitivity analysis $[25,26]$. However, the potential for significant highly nonlinear interactions between parameters makes variance-based global sensitivity analysis a more appropriate choice when comparing IUWM alternatives. Variance-based sensitivity analysis measures the contribution of uncertainty in the model inputs to the output model variance by varying inputs according to a given probability distribution, simultaneously evaluating the contribution from each individual input and the interactions between inputs [26,51,52].

Cole and colleagues [53] performed an uncertainty analysis using a Monte Carlo-based approach to determine the reliability of financial, social, and environmental performance of IUWM alternatives. Probability distributions were defined for each uncertain input. Monte Carlo samples were then generated and run through the financial, social, and environmental decision models to evaluate the full range of possible outcomes given uncertainty in the model inputs. That analysis was followed by a variance-based sensitivity analysis to calculate first order (main) and total sensitivity indices for each input. First order sensitivity indices, which show the main effect contribution of each input to the output variance [51], were used to prioritize inputs that had the most influence on alternative performance uncertainty. Total sensitivity indices, which also include the interaction effects between inputs on the output variance [51], were used to identify non-influential inputs that could be fixed in future iterations for model simplification. However, how does the IUWM decision hold up if assumptions about the future environment change?

\subsubsection{Scenarios of Alternative Futures}

Contextual uncertainty, extreme changes in the utility's operating environment, which may result in a change to the drivers, actors, and technologies defining the option space, cannot be addressed with uncertainty analysis. Scenario planning can address this limitation by providing a process for considering plausible alternative future scenarios $[23,26,54]$. The purpose of scenario planning is to identify large scale uncertain and uncontrollable external factors (e.g., climate change, population changes) that may impact the consequences of a decision [55]. Benefits of scenario planning include an enhancement of an institution's capacity to perceive, interpret, and respond to change, as well as facilitate social learning [56].

In the CRTM planning framework, the scenario planning process is used to identify critical uncertainties that affect water infrastructure to obtain a matrix of extreme alternative future scenarios. 
These scenarios are then used to "wind tunnel test" [23] the option space. The scenarios may shift the option space by changing the drivers, technologies under consideration, and the priorities of the actors. There are two levels of analysis that can then be done to address contextual uncertainty. First, the scenarios and TBL-MCDA models can be used to evaluate the performance of the alternatives in the future scenarios, focusing on the most influential inputs that were identified in the sensitivity analysis. Second, the scenarios can be used to examine whether the option space and factors used to evaluate the option space would change in each possible future.

MCDA, uncertainty analysis, and sensitivity analysis provide the structure for complex decision analysis, but do not address the socio-institutional barriers to taking a flexible, transdisciplinary approach that is needed for IUWM. A process was needed to accommodate feedback from many diverse participants throughout the study.

\subsection{Participatory Process}

Urban water management problems are influenced by local and regional conditions, planning decisions, regulations, water rights, geography, and community priorities. Participants of IUWM projects can include representatives from the different water sectors, local customers, city departments, regional interests, and regulators (Figure 5). This makes a collaborative, participatory process that is essential for success. A participatory approach to decision making improves understanding and respect for other perspectives, resulting in better technical and contextual understanding of complex problems, an increase in ownership of the outcome, the potential to address water justice issues, and the establishment of the social network that is needed to support long-term organizational adaptive capacity $[10,57,58]$. However, lack of inclusiveness, empowerment, transparency, and clear goals can lead to a poor participation process with negative outcomes, including lack of cooperation, support, and consideration for minority viewpoints [58].

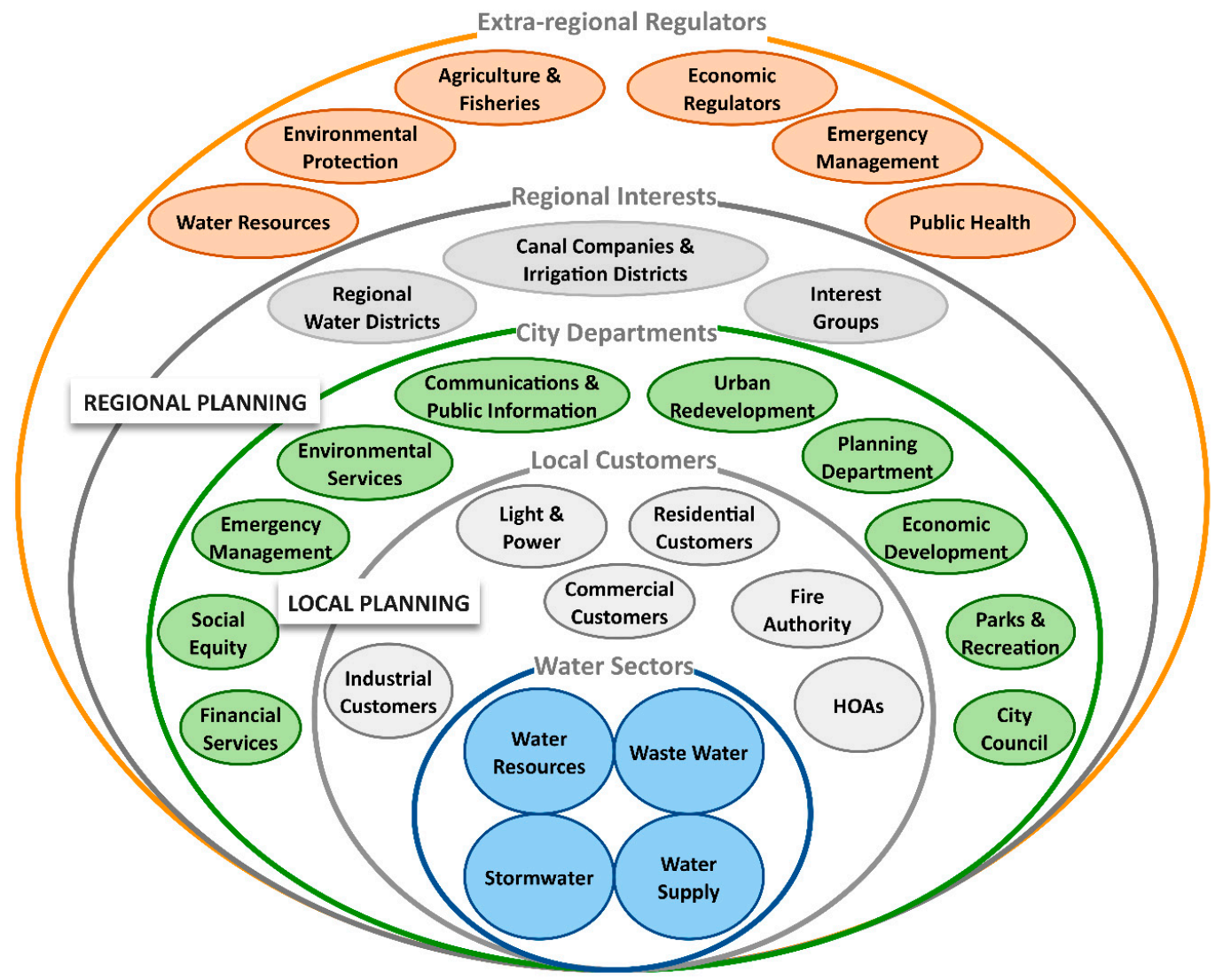

Figure 5. Integrated urban water management (IUWM) Participants. 
The CRTM planning framework enables continuous feedback loops between the project team, internal and external experts, and stakeholders (Figure 6). In the study, it included a wider range of participants, encouraged knowledge sharing among participants, and created a more agile approach. Formal meetings with utility and city department managers, as well as participation from managers in monthly progress meetings, facilitated interdepartmental collaboration. Two formal stakeholder workshops allowed the NICG to identify missing decision criteria and methodological concerns early in the study. Later, the NICG validated the revised the methods and performance indicators and assigned weights to the criteria that were used in the decision analysis. This iterative process facilitated a soft feedback loop and allowed the option space to evolve as the team consulted and presented progress to participants and received feedback to incorporate into future versions.

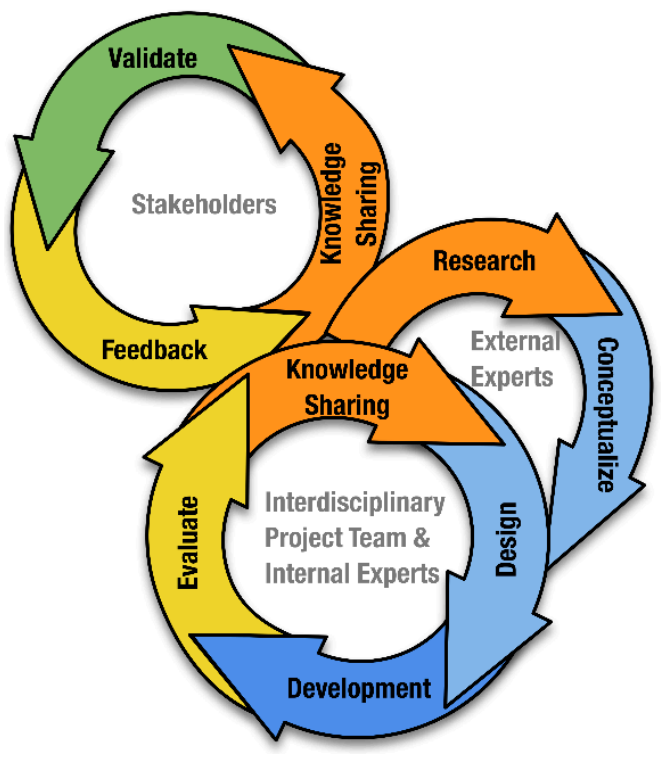

Figure 6. Participatory Approach.

While each of the four components of the CRTM framework-TBL, MCDA, uncertainty and sensitivity analyses, and participatory decision making - provide a critical piece of the puzzle, merging the components into a single framework, enabling practitioners to address a wider range of IUWM barriers. The CRTM planning framework builds on previous studies by integrating all four concepts to address the barriers to IUWM. The methodology provides further refinement of the option space (feasible infrastructure solutions) by providing more transparency into the factors (actors, technology, drivers) influencing the option space [2]. An iterative and participatory approach throughout the decision process provides insight into stakeholder priorities and attitudes toward risk, performance, and cost of new technical solutions considered, and constraints and goals. MCDA and TBL help to provide the structure and process for facilitating complex multidimensional decision problems between multiple stakeholders and facilitate stakeholder understanding of the benefits and trade-offs that are associated with alternative strategies. Uncertainty and sensitivity analyses ensure better understanding of complex problems and reduce decision risk. Any long-term infrastructure decision will require several iterations of the framework as decision makers' understanding of the problem evolves or environmental conditions and stakeholder preferences change.

\section{Impacts of the CRTM Planning Framework}

The CRTM planning framework (Figure 2) changed the factors influencing the option space in the study and allowed for further refinement of the option space by addressing participant concerns regarding the decision process. It changed the decision models that were used to evaluate the option space, improved visibility into the decision process with uncertainty and sensitivity analyses, expanded 
the number of participants, increased communication between participants, and facilitated NICG cooperation. This section explains how the CRTM planning framework changed the approach that was taken in the study and influenced the option space. For technical details regarding the dual water supply study, please refer to Cole et al. [29,53].

\subsection{TBL-MCDA Models}

Changing the decision models to preserve the complimentary lenses of sustainability and including the NICG in defining the criteria and performance indicators that were used to evaluate the alternatives resulted in more meaningful stakeholder participation and regained their support in the study. In addition, quantitative scores in each TBL category further enhanced the capacity to assess the decision.

Originally, there were 25 performance indicators organized under five main criteria. The revised approach increased the number of main criteria to 11 and evaluating those criteria from each bottom line resulted in a total of 17 financial, 15 social, and 13 environmental performance indicators [29]. Of particular interest to the group were how alternatives would affect the natural areas supported by the urban water corridors. This resulted in the addition of a criterion that favored the fourth alternative (separated irrigation systems).

\subsection{Addressing Uncertainty}

The uncertainty analysis helped to refine the option space by allowing stakeholders to consider the performance of the alternatives over the full range of possible inputs and identify the most robust alternatives given future uncertainty. It also allowed stakeholders to identify where there was overlap in alternative performance, which is important for future analysis. The sensitivity analysis provided insight into which inputs were driving output variance and it should be the focus of future analysis. It also showed which inputs did not impact output variance for model simplification in future analysis. The results showed that the key factors driving uncertainty in the alternatives' financial, social, and environmental performance were regulatory and political in nature rather than technical, highlighting the importance of including regulators, community, and regional stakeholders in the decision making process [53]. Scenario planning was added to the methodology to evaluate extreme future uncertainties that cannot be addressed with uncertainty analysis, but was not done as part of the dual water systems study.

\subsection{Expanding Participatory Decision Making}

Initially, the project participants consisted of eight participants from three departments. However, snowball sampling expanded the number of participants and departments involved as the team's understanding of the problem and people affected by the decision improved. Ultimately, the study included 41 participants representing 26 departments from the university, city, region, state, and water technology providers (Figure 7). Collaborating among a large group of participants made integrating a more iterative participatory process throughout the study essential.

The stakeholders that were included in this study were representatives from city, utility, and university departments (Figure 7: NICG, Project Team, Project Sponsor). While local government participants are key stakeholders, the implementation of IUWM requires additional buy-in from customers, other stakeholders and regulators. These groups were not included in this initial study but are discussed further in the Discussion Section.

Engaging in a soft feedback loop process resulted in several important changes. Participant feedback expanded the evaluation factors and the option space as stakeholders shared community values and priorities, other city managers shared departmental goals, and multidisciplinary experts revealed financial, technical, regulatory, or political constraints. It gave study participants a more holistic view of the problem and a better understanding of different stakeholders' attitudes toward risk. 


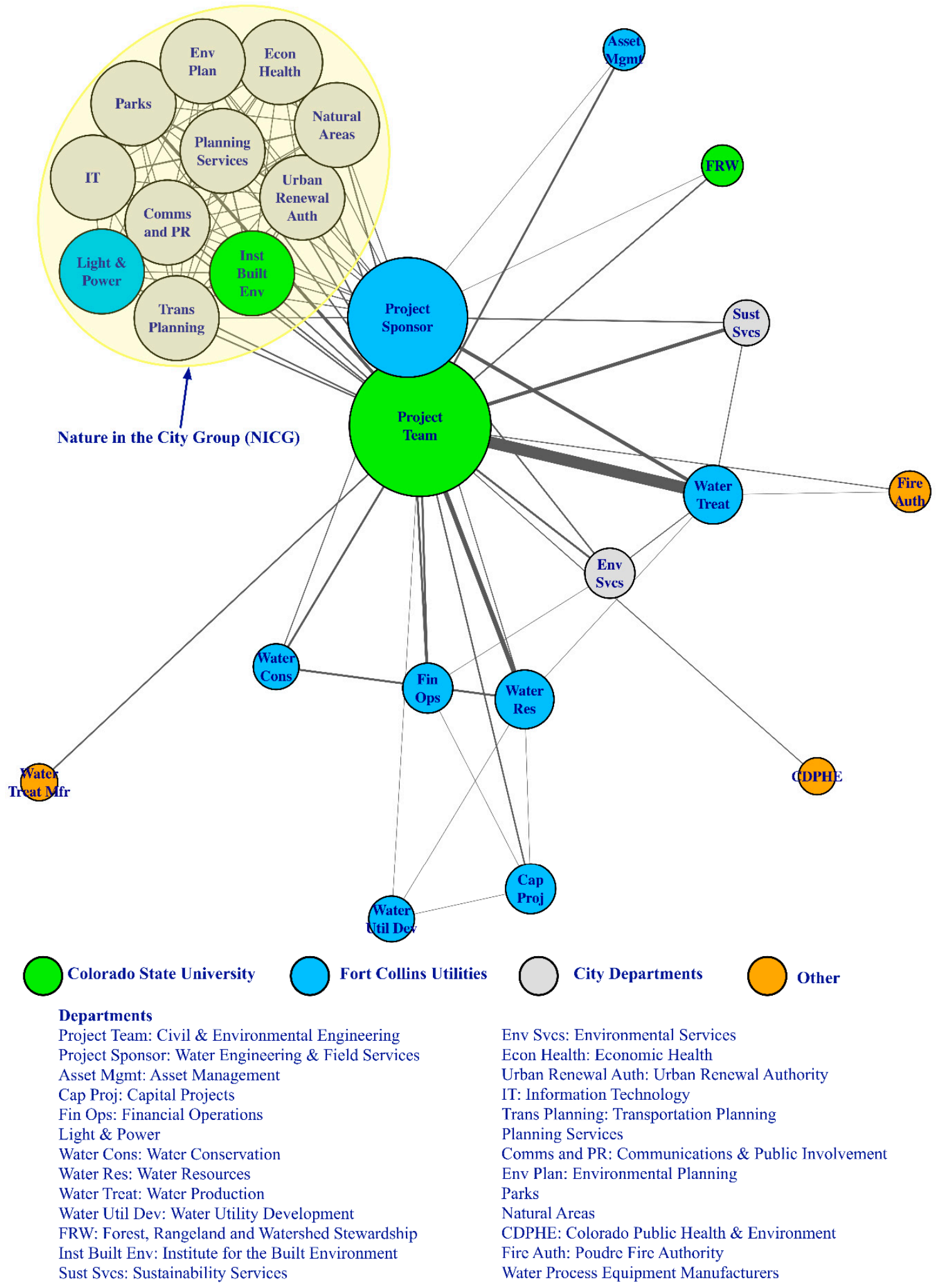

Figure 7. Knowledge sharing among study participants (Force-directed graph using Fruchterman \& Reingold algorithm. Nodes represent the 26 departments/organizations involved in the study. Node size represents the number of shortest paths going through that department (betweenness centrality) (igraph $\mathrm{R}$ package). Connections represent knowledge sharing communications. Thickness of connections represent the number of communications. Meetings, workshops, and phone conversations were represented as reciprocal communications and emails as unidirectional communication). 
The participatory approach (Figure 6) taken in the CRTM framework that was used in the dual water systems study led to a greater level of interaction among study participants. The original methodology would have resulted in a star shaped social network graph of communication among participants with all communication flowing to and from the project team. Instead, there were more communication connections between participants than originally anticipated (Figure 7). The exchange of knowledge between the project team, utility, and other city departments led to a better understanding of how the project would affect the objectives of other city departments, how it fits into the city's overall goals, and the priorities of the local community.

\section{Discussion}

The original methodology in the dual water systems study in Fort Collins led to the confrontation of several challenges to IUWM that were identified in previous studies. However, more inclusive participation throughout the study and maintaining a cooperative approach allowed for the identification of obstacles to project success and the adaptation of a decision framework to address those obstacles. The resulting CRTM planning framework was successful in overcoming some of the identified barriers to IUWM, but did not address 'lock-in effects of legacy systems' [2] or regulatory hurdles that need to be considered in future work. This framework stresses the importance of involving stakeholders and experts from the beginning of a project in an iterative process to ensure contextual and technical understanding of the problem, empower stakeholders, and garner support. The importance of integrating a hybrid TBL-MCDA approach to provide structure for the decision analysis, ensure that problems are evaluated from the three lenses of sustainability, and make transparent to stakeholders the benefits and tradeoffs that are involved with alternatives. It also addresses the need for the inclusion of techniques, such as uncertainty analysis, scenario planning, and sensitivity analysis, which account for future uncertainty and provide a better understanding of the increasingly complex problems water managers are asked to solve. The focus of this study was on IUWM decision making in a public utility context. However, the CRTM concepts could potentially be applied to other contexts, as the challenges that are faced by IUWM decision makers are similar to other public infrastructure decisions involving complex systems and multiple stakeholders.

\subsection{Addressing IUWM Barriers}

The CRTM planning framework (Figure 2) integrates TBL, MCDA, uncertainty and sensitivity analyses, scenario planning, and a participatory process to address obstacles to IUWM planning. Limitations of the original methodology and the participant needs identified for project success arose from several of the IUWM barriers that were previously identified in the introduction section. Several researchers have combined more than one method to increase the effectiveness of their approach. Hyde et al. [25] and Sapkota et al. [39] both proposed frameworks that utilize MCDA and uncertainty analysis to evaluate sustainable water alternatives. Scholten et al. [26] took this a step further and applied MCDA, uncertainty analysis, and global sensitivity analysis to water supply infrastructure planning. Scholten et al. [19] and Karaca et al. [23] both use MCDA and scenario planning to evaluate water infrastructure decisions. Ultimately, the synergy that is created from integrating these different methods in a single planning framework enables decision makers to overcome many IUWM barriers (Table 1).

The project identified two feasible dual water supply alternatives for the city to consider in future planning, centralized water treatment with dual distribution and separated irrigation systems. The revised approach garnered buy-in from stakeholders and water managers would like to implement a pilot study. However, 'lock-in effects of legacy systems' [2] still pose an obstacle to implementation. In a built out urban area, implementing alternative solutions is less difficult in redevelopment or new development areas on the fringe of the service area. There is interest in a neighborhood planned for redevelopment that is located close to the central water treatment facility for implementation, but this remains in the preliminary discussion phase. Marlow et al. [2] point out that the implementation of 
new solutions will likely happen incrementally over time. Maintaining momentum to implement new strategies will require concerted effort and ongoing community engagement.

Table 1. How the CRTM planning framework addressed barriers to IUWM decision making.

\begin{tabular}{|c|c|}
\hline $\begin{array}{l}\text { IUWM Barriers } \\
\text { Encountered }\end{array}$ & How the CRTM Planning Framework Addressed Barriers \\
\hline $\begin{array}{l}\text { Lack of collaborative } \\
\text { governance }\end{array}$ & $\begin{array}{l}\text { Addressed institutional obstacles to collaboration through an informal, flexible, } \\
\text { participatory process that included multiple stakeholder groups, water sectors, and city } \\
\text { departments. Revised methodology regained stakeholder support and further } \\
\text { participation in the study. }\end{array}$ \\
\hline Risk averse culture & $\begin{array}{l}\text { Stakeholder participation was key to understanding different types of risk and attitudes } \\
\text { towards those risks. Uncertainty and sensitivity analyses, and scenario planning provide a } \\
\text { structured methodology for addressing decision risk. }\end{array}$ \\
\hline $\begin{array}{l}\text { Bias toward technocratic } \\
\text { solutions }\end{array}$ & $\begin{array}{l}\text { Inclusion of stakeholders in a collaborative, iterative approach throughout the project } \\
\text { allowed for better contextual understanding of the human, technological and ecological } \\
\text { dimensions. TBL-MCDA allowed for inclusion of more subjective criteria important to } \\
\text { stakeholders in the decision analysis. }\end{array}$ \\
\hline $\begin{array}{l}\text { Vertical \& horizontal } \\
\text { fragmentation }\end{array}$ & $\begin{array}{l}\text { Managers from different "silos" were included through informal meetings, inclusive } \\
\text { monthly progress meetings, and stakeholder workshops. This participation facilitated the } \\
\text { identification of areas of alignment and conflict, which allowed for a more } \\
\text { holistic approach. }\end{array}$ \\
\hline $\begin{array}{l}\text { Lack of information } \\
\text { and/or appropriate tools }\end{array}$ & $\begin{array}{l}\text { Stakeholder and expert involvement in an iterative, participatory process allowed for } \\
\text { knowledge sharing between participants resulting in a comprehensive approach to the } \\
\text { problem. TBL-MCDA, uncertainty analysis and sensitivity analysis provided a structural } \\
\text { framework for the decision process. }\end{array}$ \\
\hline Increased complexity & $\begin{array}{l}\text { Integration of a participatory process increased understanding of the problem from } \\
\text { multiple perspectives. Sensitivity analysis can help identify key inputs driving the } \\
\text { uncertainty in the decision results and simplify the decision problem for future iterations. }\end{array}$ \\
\hline $\begin{array}{l}\text { Decisions driven by } \\
\text { financial metrics }\end{array}$ & $\begin{array}{l}\text { Hybrid TBL-MCDA approach provided transparency into all costs and benefits by } \\
\text { analyzing the decision problem through the three pillars of sustainability and including } \\
\text { incommensurable and intangible performance criteria in a quantitative manner. }\end{array}$ \\
\hline
\end{tabular}

\subsection{Community Values}

Several water utility sustainable practices and technical solutions exist, but there is a gap in the adoption of these systems by local governments. Landis [59] found that less than half of the 125 US water utilities surveyed are using sustainability practices or technologies and only $21 \%$ had a sustainability plan or policy approved by the local government. Fort Collins is a progressive city with a Sustainability Services Department and it has adopted sustainability and climate action plans. The local community has a history of innovation and investment in its future focused on ecological and social values [60,61]. Smithsonian Lemelson Center for the Study of Invention and Innovation recognized Fort Collins as a place of invention due to its "overarching character of collaboration" between the Colorado State University, city government, and local businesses [61]. Residents have approved sales tax increases to create open space and land conservation enabling the preservation of 39 natural areas [60]. The Fort Collins' community focus on the environmental and social benefits of nurturing these natural areas had a significant effect on the option space and the key drivers that were included to evaluate alternative performance. This demonstrates how community values and the presence of a local university committed to community engagement can shape the option space further reinforcing the need for early engagement with the community.

The next steps involve decision makers consulting the public on the benefits they value the most to inform the decision process. Choice experiments, which are commonly used to measure individual preferences regarding ecosystem services [62-64], can be applied to assess the value the public places on the benefits of the alternatives. 


\subsection{Institutional Obstacles to Collaborative Decision Making}

Implementation of IUWM may require fundamental changes in the structure and regulatory control of water services. The study that is discussed here focused mainly on water supply, but IUWM can involve wastewater, stormwater, and recycled water, as well as associated issues of green infrastructure. Obtaining approvals and buy-ins from customers, other stakeholders, and regulators can involve lengthy and conflictual processes involving law, politics, finance, and public opinion.

As they undertake their work duties, stakeholders within a local government represent the public in part, but planners and managers are often surprised by the extent of public resistance to change, funding increases and perceived risk. To confront the possible barriers, it is good practice to consider customers and ratepayers, the broader public, and regulators as other stakeholders. Understanding how customers view the risks, benefits, and possible changing roles and responsibilities that are associated with alternative strategies is essential to understanding the full context of the problem, different stakeholder biases, and customer adoption [48,65]. Engaging the broader public early in the soft loop process helps to inform the public, build trust, and prevent misinformation that could lead to public rejection of alternative strategies $[9,65,66]$. Even with broad public acceptance, risk-averse regulatory bodies have little incentive to change long-standing practices that are designed to avoid past failures. For example, even while homeowners have been enthusiastic to use graywater or roof runoff for irrigation, regulatory bodies have often prohibited the practice [67].

Ultimately, gaining approval from local government stakeholders within an organization is a necessary first step, but the most that can be gained at that stage is the development of an initial plan. This must then be converted into an action program that includes planned public participation at different stages [68]. Even then, the public may not take interest until a definite issue, such as a rate or tax increase, is in front of them. Opposition can surface at any stage and must be anticipated.

\subsection{Long-Term Action Program}

Implementation of alternative strategies occurs over time. As time passes, the external conditions change, new technologies become available, and stakeholder opinions and objectives change. The CRTM framework addresses this with future iterations of the framework. However, integrating the CRTM framework with a dynamic adaptive policy plan [69] would provide a roadmap for identifying when water managers should engage in the next CRTM cycle. As current strategies reach a tipping point, "conditions under which an action no longer meets the clearly specified objectives" [69], the CRTM framework can be used to re-evaluate the option space.

\section{Conclusions}

This manuscript details the CRTM planning framework that evolved from a study evaluating alternative water supply strategies for a utility in Colorado. The original linear, technocratic decision process was limited in facilitating ongoing input from a diverse group of participants, evaluating alternatives from the TBL, and quantifying and evaluating decision risk. These limitations ultimately led to resistance from stakeholders. In response to these challenges, a new framework evolved that provided a structured methodology for integrating TBL into MCDA, incorporated uncertainty and sensitivity analysis, and provided a more agile participatory approach to the problem. The framework addresses barriers to IUWM decision making by building institutional capacity through a more flexible and participatory approach; integrating the three pillars of sustainability, incommensurate criteria, and stakeholder preferences; reducing decision risk and improving transparency and considering extreme futures. The CRTM framework could potentially be more broadly applied to other complex public infrastructure decisions.

The CRTM framework was successful in regaining stakeholder support. Stakeholder feedback was not only the impetus for the CRTM framework, but it also impacted the criteria that were used to refine the option space. The TBL-MCDA models ensured a better balance between financial, social, 
and environmental performance in the decision analysis. The agile participatory process increased the number and diversity of participants that were involved in the study and increased knowledge sharing among participants. This allowed for a more holistic approach to the decision process, more collaboration between city departments, and better alignment with community values.

Problem complexity was addressed with uncertainty and global sensitivity analyses. Uncertainty analysis helped to refine the option space by showing how uncertainty in decision model inputs affected the performance of the alternatives. Global sensitivity analysis provided more transparency for model simplification and the identification of key inputs for future analysis.

There were some key lessons learned from the study that practitioners should keep in mind when applying the CRTM planning framework. Involving stakeholders early in the process and taking a flexible, adaptive approach provides local context to the problem, avoids a technocratic approach, and facilitates stakeholder participation and buy-in. In addition to coordinating across city departments, addressing issues of long-term uncertainty and risk requires integrating tools, like uncertainty analysis, global sensitivity analysis, and future scenario planning into the planning framework. Determining the level of detail that is appropriate for the type of analysis being conducted and remaining inclusive without creating needless complexity is challenging and a method for minimizing problem complexity is essential. Finally, maintaining momentum for IUWM projects is difficult due to long planning horizons. A project timeline that includes well timed, cyclic inclusion of stakeholders throughout the process can help to maintain public interest and organizational momentum.

Future work should focus on strengthening linkages with external stakeholders. This study attempted to overcome institutional barriers by focusing on horizontal collaboration at the city governance level. However, the study lacked direct public participation and vertical collaboration between local and more regional interests. Groups representing the public, utility customers, regional water utilities, canal companies, irrigation districts, and other regional interest groups should be included in future consideration of the feasible alternatives and policies for future implementation of the alternative strategies.

Author Contributions: Conceptualization, J.C. and S.S.; methodology, J.C., S.S. and J.H.; validation, S.S., N.G., G.P. and J.H.; formal analysis, J.C.; investigation, J.C., S.S. and N.G.; data curation, J.C.; writing-original draft preparation, J.C.; writing-review and editing, J.C., S.S., N.G., G.P. and J.H.; visualization, J.C.; supervision, S.S.; project administration, S.S. and J.C.; funding acquisition, S.S. and N.G.

Funding: This work was funded by the City of Fort Collins Utilities and the National Science Foundation (NSF) Sustainability Research Network (SRN) Cooperative Agreement 1444758.

Conflicts of Interest: The authors declare no conflict of interest.

\section{References}

1. Larsen, T.; Gujer, W. The concept of sustainable urban water management. Water Sci. Technol. 1997, 35, 3-10. [CrossRef]

2. Marlow, D.; Moglia, M.; Cook, S.; Beale, D. Towards sustainable urban water management: A critical reassessment. Water Res. 2013, 47, 7150-7161. [CrossRef] [PubMed]

3. Karl, T.R.; Melillo, J.M.; Peterson, T.C. Global Climate Change Impacts in the United States; Cambridge University Press: New York, NY, USA, 2009.

4. American Water Works Association (AWWA). 2015 AWWA State of the Water Industry Report; American Water Works Association: Denver, CO, USA, 2015.

5. Hering, J.G.; Waite, T.D.; Luthy, R.G.; Drewes, J.E.; Sedlak, D.L. A changing framework for urban water systems. Environ. Sci. Technol. 2013, 47, 10721-10726. [CrossRef] [PubMed]

6. Brown, R. Local institutional development and organizational change for advancing sustainable urban water futures. Environ. Manag. 2008, 41, 221-233. [CrossRef] [PubMed]

7. Lebel, L.; Grothmann, T.; Siebenhuner, B. The role of social learning in adaptiveness: Insights from water management. Int. Environ. Agreem. 2010, 10, 333-353. [CrossRef] 
8. Bahri, A. Integrated Urban Water Management; TEC Background Papers; Global Water Partnership: Stockholm, Sweden, 2012; Available online: https://www.gwp.org/globalassets/global/toolbox/publications / background-papers/16-integrated-urban-water-management-2012.pdf (accessed on 30 July 2017).

9. Brown, R.R.; Farrelly, M.A. Delivering sustainable urban water management: A review of the hurdles we face. Water Sci. Technol. 2009, 59, 839-846. [CrossRef] [PubMed]

10. Pahl-Wostl, C.; Craps, M.; Dewulf, A.; Mostert, E.; Tabara, D.; Taillieu, T. Social learning and water resources management. Ecol. Soc. 2007, 12, 2. [CrossRef]

11. Palme, U. Multiple conceptions of sustainable urban water systems: Problem or asset? Water Policy 2010, 12, 425-443. [CrossRef]

12. Howe, C.; Mukheibir, P. Pathways to One Water-A Guide for Institutional Innovation; Water Environment Research Foundation: Denver, CO, USA; Alexandria, VA, USA, 2015.

13. Werbeloff, L.; Brown, R. Working towards sustainable urban water management: The vulnerability blind spot. Water Sci. Technol. 2011, 64, 2362-2369. [CrossRef] [PubMed]

14. American Water Works Association. AWWA Sustainability Policy Statement (2011). Available online: http:// www.awwa.org/about-us/policy-statements/policy-statement/articleid/217/sustainability.aspx (accessed on 7 November 2016).

15. United States Environmental Protection Agency (USEPA). Planning for Sustainability-A Handbook for Water and Wastewater Utilities; EPA-832-R-12-001; United States Environmental Protection Agency: Washington, DC, USA, 2012.

16. American Society Civil Engineers (ASCE). The Role of Civil Engineer in Sustainable Development. Policy Statement 415. 2016. Available online: http://www.asce.org/issues-and-advocacy/public-policy/policy-statement-418--the-role-of-the-civil-engineer-in-sustainable-development/ (accessed on 7 November 2016).

17. Elkington, J. The Triple Bottom Line: Does It All Add Up? Earthscan: London, UK, 2004.

18. Triantaphyllou, E. Multi-Criteria Decision Making Methods: A Comparative Study; Kluwer Academic Publishers: Dordrecht, The Netherlands, 2000.

19. Scholten, L.; Scheidegger, A.; Reichert, P.; Mauer, M.; Lienert, J. Strategic rehabilitation planning of piped water networks using multi-criteria decision analysis. Water Res. 2014, 49, 124-143. [CrossRef] [PubMed]

20. Hajkowicz, S.; Collins, K. A Review of Multiple Criteria Analysis for Water Resource Planning and Management. Water Resour. Manag. 2007, 21, 1553-1566. [CrossRef]

21. Raju, K.S.; Duckstein, L.; Arondel, C. Multicriterion Analysis for Sustainable Water Resources Planning: A Case Study in Spain. Water Resour. Manag. 2000, 14, 435-456. [CrossRef]

22. Janssen, R. On the Use of Multi-Criteria Analysis in Environmental Impact Assessment in the Netherlands. J. Multi-Criteria Decis. Anal. 2001, 10, 101-109. [CrossRef]

23. Karaca, F.; Raven, P.; Machell, J.; Camci, F. A comparative analysis framework for assessing the sustainability of a combined water and energy infrastructure. Technol. Forecast. Soc. Chang. 2015, 90, 456-468. [CrossRef]

24. Kodikara, P.; Perera, B.; Kularathna, M. Stakeholder preference elicitation and modelling in multi-criteria decision analysis-A case study on urban water supply. Eur. J. Oper. Res. 2010, 206, 209-220. [CrossRef]

25. Hyde, K.; Maier, H.; Colby, C. Distance-based stochasticuncertainty analysis for multi-criteria decision analysis in Excel using Visual Basic for Applications. Environ. Model. Softw. 2006, 21, 1695-1710. [CrossRef]

26. Scholten, L.; Schuwirth, N.; Reichert, P.; Lienert, J. Tackling uncertainty in multi-criteria decision analysis-An application to water supply infrastructure planning. Eur. J. Oper. Res. 2015, 242, $243-260$. [CrossRef]

27. Balazs, C.; Lubell, M. Social learning in an environmental justice context: A case study of integrated regional water management. Water Policy 2014, 16, 97-120. [CrossRef]

28. Pearson, L.J.; Coggan, A.; Proctor, W.; Smith, T.F. A sustainable decision support framework for urban water management. Water Resour. Manag. 2010, 24, 363-376. [CrossRef]

29. Cole, J.; Sharvelle, S.; Fourness, D.; Grigg, N.; Roesner, L.; Haukaas, J. Evaluation of centralized and decentralized strategies for dual water supply: A case study. ASCE J. Water Resour. Plan. Manag. 2018, $144,1$. [CrossRef]

30. City of Fort Collins. Plan Fort Collins_Plan Summary; City of Fort Collins: Fort Collins CO, USA, 2011. Available online: https:/ / www.fcgov.com/planfortcollins/pdf/pfc-summary.pdf (accessed on 10 December 2013).

31. City of Fort Collins. Nature in the City Overview. Available online: www.fcgov.com/natureinthecity/ (accessed on 7 November 2016). 
32. Chen, R.; Wang, X.C. Cost-benefit evaluation of a decentralized water system for wastewater reuse and environmental protection. Water Sci. Technol. 2009, 59, 1515-1522. [CrossRef] [PubMed]

33. Kang, D.; Lansey, K. Dual Water distribution network design under triple-bottom-line objectives. ASCE J. Water Resour. Plan. Manag. 2012, 138, 162-175. [CrossRef]

34. Liner, B.; deMonsabert, S. Balancing the triple bottom line in water supply planning for utilities. ASCE J. Water Resour. Plan. Manag. 2011, 137, 335-342. [CrossRef]

35. City of Fort Collins. Fort Collins: TBL Analysis Map. 2012. Available online: http://www.livabilitylane.org/ files/FortCollins-TBLAM.pdf (accessed on 30 April 2018).

36. Buckler, A. Red Light, Green Light: Decision Making with SAM, the Sustainable Action Map. Cities Go Green 10-11. 2008. Available online: http://www.livabilitylane.org/files/6_SAM_overview\&examples.pdf (accessed on 30 April 2018).

37. Janeiro, L.; Patel, M.K. Choosing sustainable technologies. Implications of the underlaying sustainability paradigm in the decision-making process. J. Clean. Prod. 2015, 105, 438-446. [CrossRef]

38. Marlow, D.; Beale, D.; Burn, S. A pathway to a more sustainable water sector: Sustainability-based asset management. Water Sci. Technol. 2010, 61, 1245-1255. [CrossRef] [PubMed]

39. Sapkota, M.; Arora, M.; Malano, H.; George, B.; Nawarathna, B.; Sharma, A.; Moglia, M. Development of a framework to evaluate the hybrid water supply system. In Proceedings of the 20th International Congress on Modelling and Simulation, Adelaide, SA, Australia, 1-6 December 2013.

40. Marques, R.; Fererira da Cruz, N.; Pires, J. Measuring the sustainability of urban water services. Environ. Sci. Policy 2015, 54, 142-151. [CrossRef]

41. Zardari, N.; Ahmed, K.; Shirazi, S.; Yusop, Z. Weighting Methods and their Effects on Multi-Criteria Decision Making Model Outcomes in Water Resources Management; Springer: New York, NY, USA, 2015; ISBN 978-3-319-12586-2.

42. Cole, J.; Fourness, D.; Sharvelle, S.; Grigg, N.; Roesner, L. Fort Collins Utilities Dual Water Systems Study; Colorado State University and Fort Collins Utilities: Fort Collins, CO, USA, 2015; Available online: https://erams. com/urbanwatercenter/wp-content/uploads/2015/11/FCU_Dual_Systems_Final_Report.pdf (accessed on 1 November 2015).

43. Huang, I.; Keisler, J.; Linkov, I. Multi-criteria decision analysis in environmental sciences: Ten years of applications and trends. Sci. Total Environ. 2011, 409, 3578-3594. [CrossRef] [PubMed]

44. Hajkowicz, S.; Higgins, A. A comparison of multiple criteria analysis techniques for water resource management. Eur. J. Oper. Res. 2008, 184, 255-265. [CrossRef]

45. Belton, V.; Stewart, T. Multiple Criteria Decision Analysis: An Integrated Approach; Kluwer Academic Publishers: Boston, MA, USA, 2002.

46. Howard, A.F. A critical look at multiple criteria decision making techniques with reference to forestry applications. Can. J. For. Res. 1991, 21, 1649-1659. [CrossRef]

47. Zanakis, S.H.; Solomon, A.; Wishart, N.; Dublish, S. Multi-Attribute Decision Making: A Simulation Comparison of Select Methods. Eur. J. Oper. Res. 1998, 107, 507-529. [CrossRef]

48. Pahl-Wostl, C. Towards sustainability in the water sector-The importance of human actors and processes in social learning. Aquat. Sci. 2002, 64, 394-444. [CrossRef]

49. Erfani, T.; Pachos, K.; Harou, J. Real-options water supply planning: Multistage scenario trees for adaptive and flexible capacity expansion under probabilistic climate change uncertainty. Water Resour. Res. 2018, 54, 5069-5087. [CrossRef]

50. Kasprzyk, J.R.; Reed, P.M.; Characklis, G.W.; Kirsch, B.R. Many-objective de novo water supply portfolio planning under deep uncertainty. Environ. Model. Softw. 2012, 34, 87-104. [CrossRef]

51. Saltelli, A.; Ratto, M.; Andres, T.; Campolongo, F.; Cariboni, J.; Gatelli, D.; Saisana, M.; Tarantola, S. Global Sensitivity Analysis-The Primer; John Wiley \& Sons Ltd.: Chichester, West Sussex, UK, 2008.

52. Iooss, B.; Lemaitre, P. A review on global sensitivity analysis methods. In Uncertainty Management in Simulation-Optimization of Complex Systems: Algorithms and Applications; Gabriella, D., Carlo, M., Eds.; Springer: New York, NY, USA, 2015.

53. Cole, J.; Sharvelle, S.; Arabi, M. Confronting uncertainty in the evaluation of dual water supply strategies. Unpublished work. 2018.

54. Dominguez, D.; Truffer, B.; Gujer, W. Tackling uncertainties in infrastructure sectors through strategic planning: The contribution of discursive approaches in the urban water sector. Water Policy 2011, 13, $299-316$. [CrossRef] 
55. Stewart, T. Chapter 11-Dealing with uncertainties in MCDA. In Multiple Criteria Decision Analysis State of the Art Surveys; Figueira, J., Greco, S., Ehrgott, M., Eds.; Springer Science+Business Media Inc.: Boston, MA, USA, 2005; pp. 445-470. ISBN 0-387-23081-5.

56. Wilkinson, A.; Kupers, R. Living in the futures. Harv. Bus. Rev. 2013, 91, 119-127.

57. Baird, J.; Plummer, R.; Haug, C.; Huitema, D. Learning effects of interactive decision-making processes for climate change adaptation. Glob. Environ. Chang. 2014, 27, 51-63. [CrossRef]

58. Reed, M. Stakeholder participation for environmental management: A literature review. Biol. Conserv. 2008, 141, 2417-2431. [CrossRef]

59. Landis, A. The state of water/wastewater utility sustainability: A north American survey. J. Am. Water Works Assoc. 2015, 107, E464-E473. [CrossRef]

60. Coloradoan Staff. 10 Moments that Shaped Fort Collins History. Coloradoan. 2014. Available online: https:/ / www.coloradoan.com/story/announcements/2014/05/30/events-helped-shape-fort-collinshistory/9766921/ (accessed on 4 April 2018).

61. Garcia, A. Smithsonian showcases Fort Collins' innovation. Coloradoan. 2015. Available online: https:/ /www. coloradoan.com/story/news/2015/06/16/fort-collins-smithsonian/28795357/ (accessed on 4 April 2018).

62. Chen, W.; Hua, J.; Liekens, I.; Broekx, S. Preference heterogeneity and scale heterogeneity in urban river restoration: A comparative study between Brussels and Guangzhou using discrete choice experiments. Landsc. Urban Plan. 2018, 173, 9-22. [CrossRef]

63. Marsh, D.; Phillips, Y. Combining choice analysis with stakeholder consultation to assess management options for New Zealand's Hurunui river. Water 2015, 7, 1649-1669. [CrossRef]

64. Zander, K.; Parkes, R.; Straton, A.; Garnett, S. Water ecosystem services in Northern Australia-How much are they worth and who should pay for their provision? Public Libr. Sci. 2013, 8, 5. [CrossRef] [PubMed]

65. Mankad, A.; Tapsuwan, S. Review of socio-economic drivers of community acceptance and adoption of decentralized water systems. J. Environ. Manag. 2011, 92, 380-391. [CrossRef] [PubMed]

66. Hurlimann, A.; Dolnicar, S. When public opposition defeats alternative water projects-The case of Toowoomba Australia. Water Res. 2010, 44, 287-297. [CrossRef] [PubMed]

67. National Academy of Sciences, Engineering, and Medicine (NAS). Using Graywater and Stormwater to Enhance Local Water Supplies: An Assessment of Risks, Costs, and Benefits; The National Academies Press: Washington, DC, USA, 2016. [CrossRef]

68. National Research Council (NRC). Public Participation in Environmental Assessment and Decision Making. Panel on Public Participation in Environmental Assessment and Decision Making; Thomas, D., Paul, C.S., Eds.; The National Academies Press: Washington, DC, USA, 2008; ISBN 0-309-12399-2.

69. Haasnoot, M.; Kwakkel, J.H.; Walker, W.E.; ter Maat, J. Dynamic adaptive policy pathways: A method for crafting robust decisions for a deeply uncertain world. Glob. Environ. Chang. 2013, 23, 485-498. [CrossRef] 